\title{
Violent Crime, Residential Instability and Mobility: Does the Relationship Differ in Minority Neighborhoods?
}

\author{
Lyndsay N. Boggess • John R. Hipp
}

Published online: 4 February 2010

(C) The Author(s) 2010. This article is published with open access at Springerlink.com

\begin{abstract}
This study examines the reciprocal relationship between violent crime and residential stability in neighborhoods. We test whether the form of stability matters by comparing two different measures of stability: a traditional index of residential stability and a novel approach focusing specifically on the stability of homeowners. We also examine whether the racial/ethnic composition of the neighborhood in which this stability occurs affects the instability-violent crime relationship. To test the simultaneous relationship between residential mobility and crime we estimate a dual multivariate latent curve model of the change in the violent crime rate and the change in the rate of home sales while controlling for neighborhood socioeconomic and demographic characteristics using data from Los Angeles between 1992 and 1997. Results indicate that the initial level of violent crime increases the trajectory of residential instability in subsequent years, whether the instability is measured as homeowner turnover specifically, or based on an index of all residents. However, the effect of instability on violent crime is only apparent when measuring instability based on an index of general residential turnover and not when including the presence of owners in this measure, or when measuring it based on homeowner turnover. We consistently find that stable highly Latino communities exhibit a protective effect against violence.
\end{abstract}

Keywords Violent crime - Residential instability · Neighborhood effects · Latent trajectory modeling - Social disorganization theory

L. N. Boggess ( $ه)$

Department of Criminology, University of South Florida,

4202 East Fowler Ave, SOC 328, Tampa, FL 33620, USA

e-mail: lboggess@bcs.usf.edu

J. R. Hipp

Departments of Criminology, Law \& Society, and Sociology,

University of California, Irvine, CA, USA 


\section{Introduction}

The relationship between crime and communities has long been a focal point of criminological and sociological investigation. From the groundwork laid by the Chicago School in the 1920s, the 'neighborhood effects' literature has examined how neighborhood context affects the individual-level behavior of residents as well as the macro-level outcomes for neighborhoods such as crime and violence. In particular, social disorganization theorists argue that racial/ethnic composition, poverty, and residential instability all influence the local crime rate by disrupting residential networks that are protective factors against crime. More recently, scholars have begun focusing on the possibility that crime can also be an important catalyst for community change. Increases in crime can have negative consequences for neighborhoods, including increasing residential relocation (Morenoff and Sampson 1997) and decreasing neighborhood satisfaction (Skogan 1990). As residents relocate to safer communities, crime can also contribute to neighborhood racial transition and the concentration of poverty (Bursik 1986; South and Crowder 1997a, b).

Knowing that crime is both an outcome of neighborhood structure and an influential factor of neighborhood social and economic conditions motivates the need for research to take this simultaneous relationship into account. Few studies have done this (see White 2001 for an exception). The majority of social science investigations are limited in the degree to which they deal with this reciprocal relationship, even when using longitudinal models. We need, however, to understand not only how violent crime impacts neighborhoods in general, and residential stability more specifically, but how changes in residential stability affects crime at the same time.

In addition, it may be important to take into account the racial and ethnic composition of a neighborhood in which stability or crime occurs. That is, a growing body of literature suggests that residential stability alone is not the key for reducing crime in neighborhoods, but that the context in which this stability occurs has important implications. Scholars have suggested that residential stability in minority neighborhoods may not always have such a protective effect (Warner and Rountree 1997). Warner and Rountree (1997) concluded that although social ties were negatively associated with assault rates in white communities, social ties were not significantly related to crime in neighborhoods dominated by racial/ ethnic minorities. Likewise, whereas crime may cause increased mobility out of a neighborhood, it is possible that the racial/ethnic context in which such crime occurs may also affect residential instability. Higher rates of crime in neighborhoods with higher proportions of minority residents may be perceived as a particularly volatile combination that portends a downward trajectory for the neighborhood into the immediate future. Such a perception would likely lead to an increased rate of out-mobility.

In order to more closely examine the complex relationship between violent crime, residential stability, and racial/ethnic composition, we use a dual latent trajectory model (LTM) to estimate the impact of violent crime on the rate of homeowner residential turnover while simultaneously modeling the impact of homeowner residential turnover on the trajectory of violent crime. We employ two measures of residential instability (or, stability, as these are two ends of the same continuum): the first mirrors the approach commonly used in the literature of combining two Census variables (e.g., average length of residence and the percentage of new households in the last 5 years) into an index; the second is a more novel measure of turnover that captures the rate of residential home sales. The logic of this latter measure builds on the insight that homeowners are a particularly important source of neighborhood stability and cohesion, as we elaborate below. Note that for both of these measures, we are testing the extent to which crime brings about a 
particular form of residential mobility: that in which a household moves and is replaced by another. This type of mobility creates the presence of new households in the neighborhood, or what is generally measured as residential instability in the ecological literature. In contrast, we do not focus here on mobility in which a household leaves and is not replaced by another household (for an example of a study focusing on this type of mobility, see Morenoff and Sampson 1997). We also take into account the racial/ethnic composition of the neighborhoods in which this instability occurs by testing whether the relationship between violent crime and residential home sales is moderated by the proportion of minority residents. Our analysis focuses on the City of Los Angeles between 1992 and 1997.

\section{The Effect of Residential Instability on Crime}

Research within the social disorganization framework has suggested that certain structural conditions of communities increase the vulnerability of those communities to higher crime rates. Specifically, Shaw and McKay (1942) posited that neighborhood poverty, residential instability, and racial/ethnic heterogeneity weaken residents' attachment to the neighborhood and reduce community organization and involvement. These factors restrict social interaction among residents, which in turn impedes informal social control and order maintenance, and reduces the willingness to intervene on another's behalf. More recent work has also suggested that a greater number of single-parent households in the neighborhood reduce the ability to provide informal social control that would otherwise reduce delinquency (Roncek and Maier 1991; Rountree and Warner 1999). As the community's concern for the collective environment and its capacity to monitor and control behavior decreases, crime increases.

An extensive body of cross-sectional studies consistently substantiates the role that community (dis)organization has on crime control. Of particular interest for the present study is the relationship between neighborhood residential instability and crime. The systemic model of neighborhood structure argues that residential stability is strongly related to community attachment (Kasarda and Janowitz 1974; Sampson and Groves 1989; Bursik and Grasmick 1993) and involvement (Taylor 1996); and that residential stability leads to the formation of social networks, community cohesion, and informal social control. Social expectations, common values, and informal sanctions are therefore transmitted though social ties (Bursik and Grasmick 1993) at the same time that residents develop a cohesive community structure, supervise the neighborhood, and collectively address community incivilities (Bursik 1986). Neighborhoods with more stability therefore should have lower crime rates while neighborhoods with a more transitory populationmore neighborhood change-have greater crime and disorder because the higher rates of residential turnover disrupt social networks. There is some evidence for the association between neighborhood instability and crime (for example, see Stark 1987; Morenoff and Sampson 1997).

Although some studies have found a positive relationship between residential instability and crime rates in cross-sectional studies, it should also be noted that some studies have failed to find this effect, or even found a negative effect (e.g. Pattillo 1998; Warner and Pierce 1993; Warner and Rountree 1997). As a consequence, scholars have suggested that the context in which this stability occurs may be important. Thus, residential stability in an economically disadvantaged area may simply represent residents' financial inability to leave the area, rather than any increased sense of cohesion (Anderson 1990; Warner and Pierce 1993). Likewise, if racial/ethnic minorities are limited in their housing options due 
to various discriminating processes in the housing market, they may be constrained to a neighborhood for these reasons rather than community cohesiveness. Indeed, Warner and Rountree (1997) explored this possibility in their study of Seattle neighborhoods and found that the racial/ethnic composition of the neighborhood moderated the relationship between social ties and crime, and that residential stability was positively associated with burglary in high poverty communities. Nonetheless, we point out that studies have generally failed to explore this theoretical possibility using longitudinal data.

Furthermore, whereas prior work often only makes a distinction between the extent to which the composition of the neighborhood is white or non-white, we make a further distinction between two key minority groups of African-Americans and Latinos. This distinction may be important, as it is arguably the case that the neighborhoods numerically dominated by each of these groups are qualitatively different. First, neighborhoods with a high proportion of African-Americans traditionally tend to be economically disadvantaged neighborhoods that contain a constellation of other measures of concentrated disadvantage (such as a lower percentage of college graduates, more single parent households, high unemployment, and high rates of poverty) (e.g. Adelman et al. 2001). On the other hand, although neighborhoods with a high proportion of Latinos also often contain residents with relatively low income levels, they generally do not contain all of these other markers of concentrated disadvantage. For instance, neighborhoods with higher concentrations of Latinos tend to have lower levels of unemployment and fewer single parent households than do neighborhoods with higher concentrations of AfricanAmericans. In Los Angeles in 1990, highly African American neighborhoods (one standard deviation above the mean) have an unemployment rate of $13.7 \%$ and $25.4 \%$ of the families are single-parents. In highly Latino neighborhoods, however, the unemployment rate is $11.4 \%$ and only $18.5 \%$ of households have a single-parent. The median household income in African American communities is approximately $\$ 3,000$ less than in highly Latino neighborhoods.

Second, the mobility patterns between African American and Latino households differ. Although minority groups in general are less able to translate their economic attainment or neighborhood preferences into higher quality neighborhoods, studies consistently show that Latino households are better equipped to do so than African American residents (Alba et al. 2000; South et al. 2005). Research also continues to show that African Americans are still discriminated against in the housing market (Turner et al. 2002; Turner and Ross 2003) and remain more isolated from non-Latino white communities (Charles 2003) than any other minority group regardless of socioeconomic status (Iceland and Wilkes 2006). It is likely then that the residential turnover in African American neighborhoods is often movement between impoverished communities, whereas Latino households have more stable communities to begin with and are more likely to relocate into less poor areas when they leave.

Third, the ethnic enclave literature suggests that Latino immigrant neighborhoods might have a particularly protective effect (Wilson and Portes 1980). Despite general economic deprivation in such neighborhoods, the presence of dense network ties in these neighborhoods may foster the sort of informal social control that helps reduce crime. That is, Latino-dominated neighborhoods may foster a particularly strong sense of cohesion as these "barrios" create an "institutional completeness" (Breton 1964). This would suggest that residential stability in Latino-dominated neighborhoods would have a different effect on crime than would stability in African American-dominated neighborhoods, and perhaps also in white-dominated neighborhoods that would arguably lack such institutional completeness. 
The above considerations suggest that the relationship between residential instability and future crime in neighborhoods may differ based on the racial/ethnic composition. In neighborhoods with a high proportion of African-Americans, residential stability would likely not have the protective effect hypothesized for it in social disorganization theory. On the other hand, in neighborhoods with a high proportion of Latinos residential stability should exhibit its protective effect similar to the posited effect for white-dominated neighborhoods. We are aware of no studies testing this possibility.

\section{The Effect of Crime on Residential Stability}

Much prior research on social disorganization theory has overlooked the possibility that increases in crime may affect the community social structure. As described above, many studies employ a cross-sectional test and simply assume that the causal effect of residential instability on crime explains the relationship. However, there is a small but growing body of literature suggesting that crime itself may have a feedback effect on the social structural characteristics of the neighborhood (e.g. Bellair 2000; Sampson et al. 1997). That is, crime increases because social control is weak, but the increasing crime further decreases social control by breaking up social networks, decreasing participation in community activities and inducing residential mobility. Indeed, there is empirical evidence that crime can induce neighborhood mobility as households relocate in response to violent crime (Morenoff and Sampson 1997), to victimization (Dugan 1999), or as a response to an increased social disorder (Skogan 1990). Liska and Bellair (1995) determined that violent crime, robbery in particular, is associated with residential out-mobility and racial change in cities between 1950 and 1990. If these households leaving the neighborhood are replaced by other households, residential instability will necessarily increase. On the other hand, Morenoff and Sampson (1997) focused on the extent to which exiting households are not replaced, and found a general population loss as the number of homicides in Chicago neighborhoods increased.

In addition to inducing residential out-mobility, crime can also impact potential homeowners' decisions regarding where to move in the first place. For example, Garland and Stokols (2002) determined that middle-class families are less likely to move into a neighborhood that is perceived as dangerous or having high rates of crime, regardless of the actual crime rate. Likewise, community social and physical incivilities such as fighting and arguing between residents, litter, graffiti, and dilapidated housing are signals to potential homeowners to avoid such communities because these cues are associated with potential criminal victimization (Hunter 1978). Neighborhoods with higher crime rates are also associated with lower housing prices (Schwartz et al. 2003; Tita et al. 2006), which discourages potential homeowners from purchasing in a community where they may not profit from their investment. ${ }^{1}$ These considerations all suggest that residential instability could decrease if homeowners are unable to sell their property as a result.

Whereas there is reason to expect crime rates to affect mobility into and out of a neighborhood, it is also possible that this crime will have differential effects based on the racial/ethnic composition of the neighborhood. The logic builds on the insight of the fear of

\footnotetext{
1 Another possibility is that a reduction in crime might increase residential instability because rising home prices may lead to larger profit margins on an investment, causing homeowners to sell their home to maximize profit. We are aware of no evidence documenting such a process. Nonetheless, to the extent this is the case, it will diminish the strength of the relationship that we detect between higher crime rates and subsequent home sales volatility.
} 
crime literature that has suggested that the racial/ethnic composition of the neighborhood can affect residents' perceptions of crime (Sampson and Raudenbush 2004) and fear of crime (Liska et al. 1982). For instance, studies have shown that both black and white residents in neighborhoods with more racial/ethnic minorities report higher levels of fear of crime (Liska et al. 1982). If this fear of crime is compounded by the awareness of increasing numbers of crime events in the neighborhood, this might synergistically increase residential mobility out of the neighborhood. We test this possibility here, although we are aware of no prior tests of this hypothesis.

\section{Measuring Residential Instability}

Finally, we briefly consider the issue of how residential stability is measured in empirical work. Most commonly, residential stability is measured either as the average residential length of stay in the neighborhood, the proportion of households who moved within the past 5 years (of the Census), the proportion of residents who own their home, or some combination of these measures as an index (Garcia et al. 2007). There are two main dimensions underlying these measures. The first dimension is a direct measure of stability (either measured as length of time, or the proportion of new residents in the neighborhood). More new or short-term residents implies that they have had less time to form social relationships and may therefore be less concerned for the welfare of other residents or the community. In early work on the relationship of stability to neighborhood and social problems, Kasarda and Janowitz (1974) found that length of residency significantly and positively influenced residential attachment. Studies using length of residency have found a significant negative relationship between average length of residence and crime (Bellair 1997; Hipp 2007a). Similarly, Crutchfield et al. (1982) found a significant positive relationship between the rate of new residents moving in and violent crime, particularly homicide, in large U.S. metropolitan areas.

The second main dimension of these measures captures the presence of homeowners. In part, owners are included in such measures because they tend to live longer in the neighborhood (as leaving the neighborhood is easier for renters). However, owners as a group also represent the tendency to express more attachment to the community (Bolan 1997; Oh 2004) and to be more economically invested in the viability of the neighborhood. Indeed, studies have found that homeowners are less likely to move than renters (Barrett et al. 1994; Speare et al. 1975), and more likely to know their neighbors and be involved in social networks than renters (Blum and Kingston 1984; Campbell and Lee 1992). An increasing level of crime and disorder in the neighborhood likely translates directly into lower values for one's home (Tita et al. 2006), suggesting an economic incentive. Indeed studies have found that neighborhoods with a greater proportion of homeowners have lower rates of burglary (Ross 1977) and violence (Hipp 2007b; Krivo and Peterson 1996; Roncek 1981; Smith et al. 2000).

Given these considerations, we suggest that the residential stability of homeowners is likely of particular theoretical interest. To the extent that renters tend to be relatively transient, the homeowners of a neighborhood may be a particularly important source of stability and cohesion in a neighborhood. This would suggest that it is not enough to simply view the presence of owners, but that it would also be of interest to measure the actual level of residential stability on the part of homeowners. Although few studies have done so, we are able to assess the effect of a measure of instability that accounts for the residential mobility of homeowners, and compare the effect of this measure with a more traditional 
measure of instability based on an index combining the average length of residence and the proportion homeowners.

\section{Data}

Housing, crime, and demographic data for the city of Los Angeles are measured at the 1990 census tract level, our proxy for neighborhood. ${ }^{2}$ Based upon the 1990 census, Los Angeles had a population of approximately 3.5 million people. There were 689 census tracts in Los Angeles in 1990, but we excluded 18 tracts from the analysis because of missing crime data. We also excluded tracts based on low total population (fewer than 500 residents) or low number of owner-occupied housing units (fewer than 200 units). In those tracts, small absolute changes in the number of home sales generate large percentage changes in home sales because of low base rates of residential population. The excluded tracts tend to cluster in industrial and commercial areas where the number of housing units is sparse. Our final sample is a panel of 585 census tracts across the years 1992 to 1997. The average tract population was 4,906. The crime data used in these analyses was obtained from the Los Angeles Police Department and consists of the total number of Part I crimes per reporting district (an area approximately equal to a census tract). We apportioned this reporting district data to the appropriate census tracts using a geographic information systems (GIS) overlay function. The housing sales data were obtained from DataQuick, Inc., a private vendor of real estate data, and include information on each single-family residence sold in the City of Los Angeles between 1992 and 1997.

For this study, we focused on the rate of violent crime only, which was computed as the total homicides, aggravated assaults, and robberies per 100 residents. $^{3}$ The mean violent crime rate ranged from 2.29 per 100 in 1992 to 1.58 in 1997 for an average of 2.04 across the years of the study. This measure was natural log-transformed for the analyses to achieve a more normal distribution.

The rate of home sales was calculated as the total number of single family owneroccupied houses sold per year per tract divided by the total number of owner housing units. We then scaled this per 100 residences in order to put the rate of home sales on the same scale as the violent crime rate. On average, there were approximately 1,837 housing units per tract. The rate of home sales averaged $4.0 \%$ across the years of the study; approximately 38 homes per tract sold a year. The mean rate of home sales increased from $3.7 \%$ in 1992 to $5.7 \%$ in 1997.

Seven time-invariant predictors from the 1990 U.S. Census Summary File 3 were also included. Because the racial (and ethnic) composition of neighborhoods is one of the most salient, and sensitive, correlates of high crime rates, we included race/ethnicity measures for the two largest minority populations in Los Angeles: the proportion of African American residents and the proportion of Latino residents per tract. On average, tracts were

\footnotetext{
2 Though there are perhaps many ways to define "neighborhood," we rely on a conventional methodtracts- that has been used throughout sociological and criminological research on communities. Like many studies before us, we are constrained by data availability; in this case, our indicator of neighborhood crime was only available at the reporting district level, which is essentially analogous to the census tract. We therefore used census tracts as our proxy for neighborhoods.

3 Although measures of violent crime often include the number of rapes, we chose to limit our measure to just robbery, aggravated assault, and homicide. Though the occurrence of rape likely induces fear in local residents, the problematic and inconsistent reporting of rapes and sexual assaults would weaken our ability to make unbiased conclusions about violent crime and residential instability.
} 
Table 1 Average characteristics of los angeles census tracts, $N=585$

\begin{tabular}{lll}
\hline & Mean & SD \\
\hline Population & 4,906 & 1,727 \\
Population density (per square mile) & 4.35 & 2.72 \\
Median household income & 38,525 & 20,448 \\
Median housing value & 255,348 & 123,978 \\
Percent Black & 14.0 & 22.7 \\
Percent Latino & 32.4 & 25.6 \\
Percent white & 44.3 & 33.2 \\
Length of residency (in years) & 10 & 2.74 \\
Percent owner-occupied & 48.8 & 24.4 \\
Percent new residents (in last 5 years) & 50.6 & 11.0 \\
Rate of home sales (per 100) 1992 & 3.73 & 1.96 \\
Rate of home sales (per 100) 1993 & 3.77 & 2.02 \\
Rate of home sales (per 100) 1994 & 4.63 & 2.24 \\
Rate of home sales (per 100) 1995 & 4.63 & 2.52 \\
Rate of home sales (per 100) 1996 & 5.19 & 2.80 \\
Rate of home sales (per 100) 1997 & 5.66 & 2.98 \\
Violent crime rate (per 100) 1992 (logged) & 2.29 & 1.83 \\
Violent crime rate (per 100) 1993 (logged) & 2.19 & 1.73 \\
Violent crime rate (per 100) 1994 (logged) & 1.97 & 1.61 \\
Violent crime rate (per 100) 1995 (logged) & 1.90 & 1.55 \\
Violent crime rate (per 100) 1996 (logged) & 1.74 & 1.44 \\
Violent crime rate (per 100) 1997 (logged) & 1.58 & 1.31 \\
\hline & & \\
& & \\
\hline
\end{tabular}

14\% African American, just over 32\% Latino, and 44\% non-Latino white. Median household income (in tens of thousands of dollars) and median property value (in hundreds of thousands of dollars) were also included as indicators of neighborhood affluence; we included median household income as an independent variable in the model predicting the violent crime rate, and median housing value as an independent variable in the model predicting the rate of home sales. In 1990 the average median income across Los Angeles was $\$ 38,525$ and the median property value was $\$ 255,348$. We combined two measures of residential stability into an index: the percentage of new households in the last 5 years and the average length of residence. The percent of new households of all households averaged $50.6 \%$ across Los Angeles tracts (in 1990). The average length of stay is the average number of years residents have lived in the neighborhood; in Los Angeles, the mean length of residency was 10 years. Population density per square mile was included as a control variable. Our predictor variables are centered on the sample mean for the estimation; uncentered sample means are shown in Table 1.

To account for the possibility that the racial/ethnic composition of the neighborhood may moderate the effect of residential instability on crime trajectories, interactions were created between housing volatility in 1992 and the two race/ethnicity measures. To test whether the racial/ethnic composition moderates the effect of crime on housing stability trajectories, interactions were created between violent crime in 1992 and the two race/ ethnicity measures. All four interaction terms were divided by 100 in order to place the values in a similar metric as the other variables in the model (to minimize estimation 
problems). In ancillary models, we computed interactions of our residential stability index and these two race/ethnicity measures.

\section{Method}

We used dual latent trajectory analysis to model patterns of change in the violent crime rate and housing sales over time. Latent trajectory models, or growth curve models, are not widely employed in criminological research, but have been successfully applied in psychological studies on individual behaviors such as cigarette smoking (Windle and Windle 2001) changes in personality disorders over time (Lenzenweger and Willett 2007) and obesity (Henderson 2007). These models allow for estimation of differences between individual rates of change and therefore are appropriate when measuring human behavior, which undeniably varies between subjects. Traditional regression analysis cannot account for this between subject variation and treats the slope and intercept as equal for all cases. It is unlikely that all neighborhoods throughout Los Angeles experience change at the same rate; some communities sold more houses at an increasing rate, while others remained stable, and in undesirable areas, at a decreasing rate. It makes sense, therefore, to apply this technique to larger units of analysis such as neighborhoods, and indeed other work has done so looking at homicide trajectories in census tracts (Kubrin and Herting 2003) or the clustering of psychological characteristics in groups (Nagin 1999).

In addition, LTMs can account for simultaneous relationships between variables that ordinary regression analysis cannot account for. Traditionally, longitudinal analysis has relied on either a raw change or a residual change score to estimate between year changes, implicitly assuming that the current crime rate (for example) is dependent on the rate of crime in previous years. Latent trajectory models, however, estimate the underlying trajectory using information from the full temporal sequence, not simply the difference between two time points. This allows for an overall pattern of change across time while accounting for intercommunity differences.

Our models utilize the six waves of data from 1992 to $1997 .{ }^{4}$ A diagram of our conditional model without interaction terms is shown in Fig. 1, where alpha is the latent intercept of the rate of violent crime and beta is the latent slope of the violent crime rate; alphah and betah are the latent intercept and slope for the rate of housing sales. Violent 92 through violent 97 are the natural logged observed rate of violent crime, and sales 92 through sales 97 are the rate of residential home sales (per 100 units). We simplify the diagram by representing our seven time-invariant predictors in a single box. Errorl and errorh1 through error7 and errorh7 represent the disturbance (or variability) around our observed measures; a_error, ah_error, b_error, and bh_error represent the disturbance around our latent measures. Covaah and covbbh represent the covariance between the intercepts (alpha and alphah) of crime and housing, and the covariance between the slope (beta and betah) of crime and housing.

Our estimation adopted the following steps. First, we estimated "unconditional" models without covariates for the violent crime rate and home sales in order to determine the functional form of these trajectories over time. Second, we estimated our full model in which the predictors described above (excluding the residential stability index) are allowed to predict both the latent intercepts and latent slopes of housing volatility and violent crime

\footnotetext{
${ }^{4}$ Multicollinearity among the other exogenous variables was not an issue; all VIF scores were less than 10, which is generally considered the maximum acceptable level of multicollinearity (Kennedy 1998).
} 


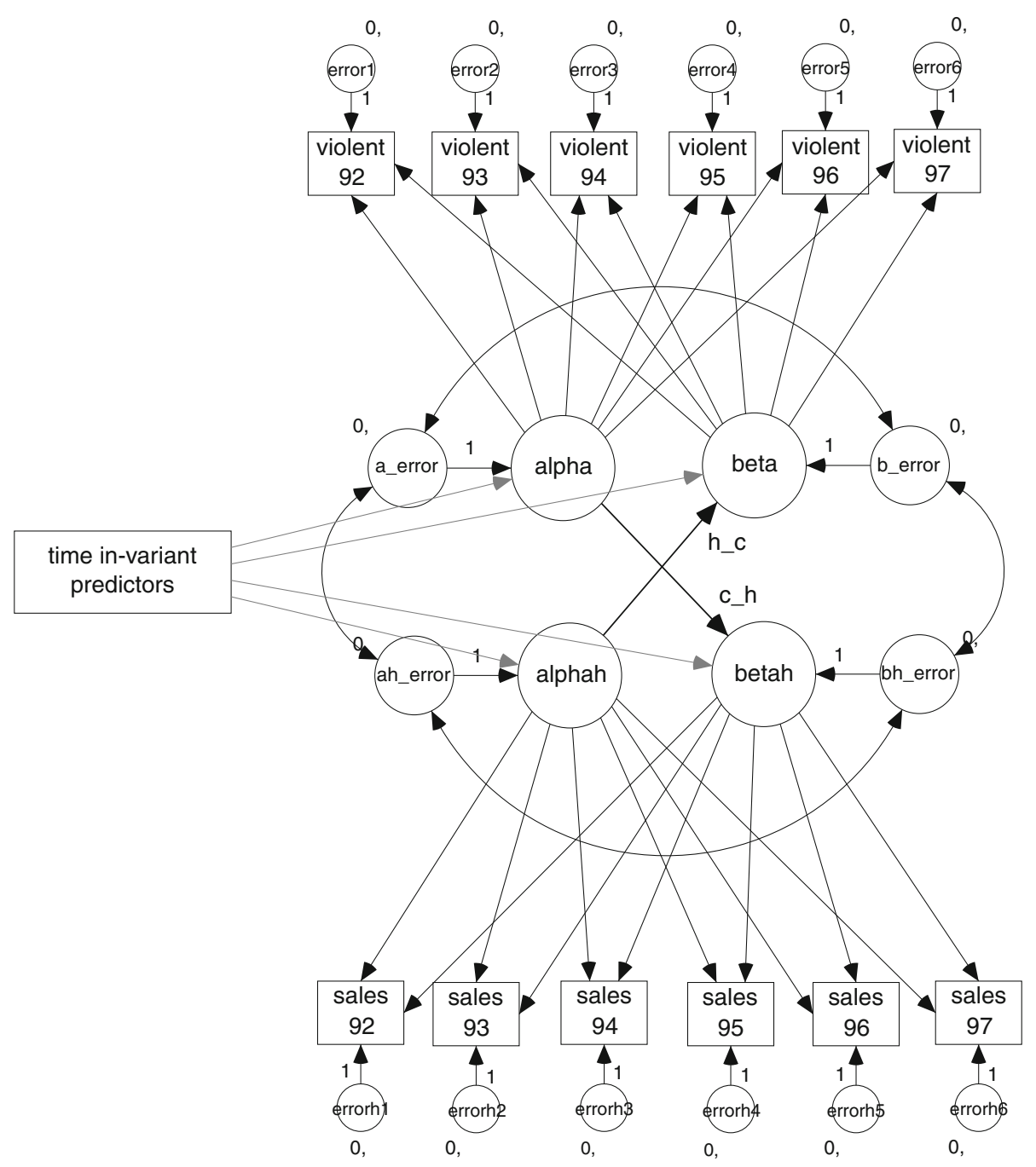

Fig. 1 Conditional model of the relationship between the violent crime rate and the rate of home sales controlling for neighborhood characteristics, 1992-1997

simultaneously. This same model also allows us to test our key hypotheses: whether the latent intercept of violent crime affects the trajectory of housing volatility over this time period, and whether the latent intercept of housing volatility affects the violent crime trajectory over the period. Third, we estimated a model that tested whether the race/ethnicity of the neighborhood moderated these relationships between housing volatility and violent crime by including the interaction variables described above. Fourth, we estimated similar models substituting an index of residential stability for our housing volatility measure to compare the effect of general residential stability to that specifically of homeowners. In these single LTMs (of crime), the random intercept of home sales volatility was replaced with the index of residential stability in 1990, and the random slope of home sales volatility 
was replaced with the change in the index of residential stability from 1990 to 2000. All models were estimated using maximum likelihood estimation in AMOS 5.0.

\section{Results}

\section{Unconditional Model}

Unconditional LTMs for the violent crime rate and residential home sales were estimated to examine the overall trajectory and test for neighborhood variability over time. We estimated our models with linear, unstructured (freed-loading), and quadratic trajectories. In the linear model, the model implied rate of change is consistent across the years of the study, whereas in the freed-loading model the impact of time is allowed to vary. We determined that the pattern of change in the crime rate trajectory over time is best fit nonlinearly in the unstructured model. ${ }^{5}$ That is, the rate of change across time is not constant: the violent crime rate decreases more substantially in the first years of the study than in the latter. The following results then are based on the freed-loading model.

The mean value of the violent crime rate at the starting point (the intercept) was 0.195 and the average between-wave change in slope is -0.054 (or a reduction of approximately $5.4 \%$ per year). The negative coefficient on the slope implies that the mean violent crime rate is decreasing through 1997. Our conditional models will therefore compare the relative change in crime among tracts: those with positive slopes may in fact experience a decrease in crime, however, this will be a smaller decrease than that of other neighborhoods. The variance for both the intercept and slope of the violent crime trajectory were significant, indicating neighborhood variability in both the initial rate of violent crime in 1992 and the rate of change in violent crime over time.

Turning to the home sales LTM, we concluded that a freed-loading model was also the best representation of the residential home sales trajectory over the time period. Like the violent crime LTM, the chi-square for the unconditional sales model is significant; alternative summary fit indices, however, suggest that the model fits the data well, though it is not as good a fit as the violent crime LTM. ${ }^{6}$ The results show that the average rate of home sales in 1992 was 3.76 per 100 homes, and the average annual increase in the rate of sales

\footnotetext{
5 Whereas the linear model codes time in an equally increasing value for each year, the unstructured model constrains the first time point to a value of zero and the last time point to a value of one, and then freely estimates the nonparametric functional form for the intervening time points. For the linear violent crime LTM the chi-square test of overall fit yielded $\chi^{2}=81.8, d f=16$, and $p<.001$, whereas the freed-loading model had a $\chi^{2}=51.4, d f=12$, and $p<.001$. A nested test shows that the freed-loading model fits significantly better $\left(\chi^{2}=30.4, d f=4, p<.001\right)$. The approximate fit measures suggest that this freedloading model fits quite well with an IFI $=.995$ (compared to .991 for the linear model). Given that values greater than .90 are considered a good fit, this is an excellent fit. We also used the root-mean-square error of approximation index of fit (RMSEA), which builds on the non-central $\chi^{2}$ distribution. Values closest to 0 indicate a good fit. The RMSEA values indicate that the unstructured model (RMSEA $=.075(\mathrm{CI}=.055$ $.097)$ ), fit better than the linear model $.084(\mathrm{CI}=.066 .102)$. We also tested a quadratic trajectory model and found it to fit similarly to the unstructured model. The estimated value of the quadratic latent term, however, was not significantly different than 0 , therefore, we used the unstructured model.

${ }^{6}$ The linear home sales model had a $\chi^{2}=181.1, d f=16, p<.001$, whereas the freed-loading model had a $\chi^{2}=111.1, d f=12, p<.001$. Again, the nested test shows the freed-loading model had a better fit $\left(\chi^{2}=70.0, d f=4, p<.001\right)$. The IFI of .971 (compared to .95 for the linear model) also suggests a very good fit. The RMSEA $=.119(\mathrm{CI}=.99 .139)$ also shows a better fit than the linear model $(\mathrm{RMSEA}=.133$ (CI .116 .151). The quadratic trajectory model did not fit as well as the unstructured model (IFI $=.957$, and $\mathrm{RMSEA}=.143(\mathrm{CI}=.123 .164)$.
} 
Table 2 Regression results for conditional latent trajectory model for the relationship between the rate of violent crime and the rate of residential home sales without interaction effects, 1992-1997, $N=585$

\begin{tabular}{|c|c|c|c|c|}
\hline Parameter & $\begin{array}{l}\text { Violent crime } \\
\text { intercept }\end{array}$ & $\begin{array}{l}\text { Violent crime } \\
\text { slope }\end{array}$ & $\begin{array}{l}\text { Home sales } \\
\text { intercept }\end{array}$ & $\begin{array}{l}\text { Home sales } \\
\text { slope }\end{array}$ \\
\hline Violent crime intercept & - & - & - & $\begin{array}{l}5.62848 * * * \\
(0.83183)\end{array}$ \\
\hline Home sales intercept & - & $\begin{array}{l}-0.00234 \\
(0.00145)\end{array}$ & - & - \\
\hline Proportion African American & $\begin{array}{l}0.00291 * * * \\
(0.00018)\end{array}$ & $\begin{array}{l}-0.00125^{* * * *} \\
(0.00010)\end{array}$ & $\begin{array}{l}-0.02219 * * * \\
(0.00386)\end{array}$ & $\begin{array}{l}-0.01698 * * * \\
(0.00470)\end{array}$ \\
\hline Proportion Latino & $\begin{array}{l}0.00111 * * * \\
(0.00018)\end{array}$ & $\begin{array}{l}-0.00006 \\
(0.00011)\end{array}$ & $\begin{array}{l}-0.03818^{* * * *} \\
(0.00422)\end{array}$ & $\begin{array}{l}-0.02350 * * * \\
(0.00446)\end{array}$ \\
\hline Median housing value & - & - & $\begin{array}{l}-0.30801 * * * \\
(0.09157)\end{array}$ & $\begin{array}{l}0.02759 \\
(0.09452)\end{array}$ \\
\hline Median income & $\begin{array}{l}-0.13262^{* * * *} \\
(0.02699)\end{array}$ & $\begin{array}{l}0.03141 * \\
(0.01497)\end{array}$ & - & - \\
\hline Population density & $\begin{array}{l}0.00754 * * * \\
(0.00169)\end{array}$ & $\begin{array}{l}0.00024 \\
(0.00095)\end{array}$ & $\begin{array}{l}0.14855 * * * \\
(0.02922)\end{array}$ & $\begin{array}{l}0.10006^{* * *} \\
(0.03126)\end{array}$ \\
\hline
\end{tabular}

* Significant at $\alpha<.05$, ** significant at $\alpha<.01$, *** significant at $\alpha<.001 ;$ standard errors in parentheses

is approximately 1.9 sales per 100 homes. The variances of the intercept and slope were significant, confirming between neighborhood variability in the starting rate of home sales and the trajectory of sales.

\section{Conditional Models}

We next test our key hypotheses by combining the previous two models into a dual LTM and simultaneously testing whether the home sales intercept significantly predicts the violent crime slope, and whether the violent crime intercept significantly predicts the home sales slope. The results in Table 2 show clearly that whereas there is no evidence that home sales volatility increases the subsequent trajectory of violent crime-in fact, the coefficient is somewhat negative, though not significant - there is strong evidence that higher rates of violent crime result in a steeper increase in home sales volatility over the following years $(b=5.628, p<.001)$. That is, more violent neighborhoods tend to have increased residential turnover over time, as a one percent increase in the violent crime rate results in a 1.5 percent increase in the home sales trajectory for an average tract. ${ }^{7}$ These findings are inconsistent with the hypothesis in social disorganization theory that residential instability leads to more violent crime.

Consistent with prior research, we find that the racial and ethnic composition of a neighborhood is associated with local violent crime rates. The proportions of African Americans and Latinos are positively and significantly related to the intercept of the violent crime rate. Controlling for all other covariates, neighborhoods with larger proportions of African American $(b=0.0029, p<.001)$ and Latino $(b=0.0011, p<.001)$ residents have higher initial violent crime rates in 1992. There is no evidence, however, that these

\footnotetext{
7 This is calculated as follows: given the logarithmic form for the violent crime rate, a .01 change in this measure represents a 1 percent increase in violent crime. This .01 increase results in a .056 increase in the number of home sales per 100 homes. Given that the average neighborhood had a home sales rate of 3.73 in 1992 , this translates into a $1.5 \%$ increase $(.056 / 3.73=.015)$.
} 
neighborhoods experience increasing violent crime trajectories over this period. In fact, neighborhoods with a greater proportion African Americans actually experience a slight decreasing rate of violent crime over the subsequent years $(b=-0.00125, p<.001)$. That is, a one percentage point increase in African American residents is related to $0.10 \%$ decrease in the trajectory of violent crime controlling for all other covariates. The size of the Latino population is not significantly associated with the change in the violent crime rate over time. In sum, neighborhoods with more racial/ethnic minorities have higher rates of violent crime in 1992, but no evidence of increasing rates of violent crime beyond that point.

The racial and ethnic makeup of communities is also associated with residential home sales. Areas with more minority residents have lower rates of housing sales; both the proportion of African Americans $(b=-0.0222, p<.001)$ and Latinos $(b=-0.0382$, $p<.001)$ in a neighborhood are significantly and negatively related to the initial rate of home sales in 1992. This implies that such neighborhoods have lower rates of housing turnover among owners. Furthermore, we see that these neighborhoods with more minority residents also experience decreasing sales over the subsequent years, as neighborhoods with larger percentages of African Americans $(b=-0.0287, p<.001)$ and Latinos $(b=-0.0216, p<.001)$ experience relatively fewer home sales than neighborhoods with more white residents. A one percentage point increase in the proportion African American or Latino residents is related to a nearly $0.5 \%$ decrease in the slope of home sales for an average tract. These findings imply that the size of the Latino population in a neighborhood has no impact on the trajectory of violent crime over time, but reduces the magnitude of the

Table 3 Regression results for full conditional model (including interaction effects) of the relationship between the rate of violent crime and the rate of home sales, 1992-1997, $N=585$

\begin{tabular}{|c|c|c|c|c|}
\hline Parameter & $\begin{array}{l}\text { Violent crime } \\
\text { intercept }\end{array}$ & $\begin{array}{l}\text { Violent crime } \\
\text { slope }\end{array}$ & $\begin{array}{l}\text { Home sales } \\
\text { intercept }\end{array}$ & $\begin{array}{l}\text { Home sales } \\
\text { slope }\end{array}$ \\
\hline Violent crime intercept & - & - & - & $\begin{array}{l}5.62590 * * * \\
(0.83181)\end{array}$ \\
\hline Home sales intercept & - & $\begin{array}{l}-0.00227 \\
(0.00145)\end{array}$ & - & - \\
\hline African American * Violent crime & - & - & - & $\begin{array}{l}3.7529 \\
(2.8424)\end{array}$ \\
\hline Latino $*$ Violent crime & - & - & - & $\begin{array}{l}-0.63161 \\
(2.2409)\end{array}$ \\
\hline African American $*$ Home sales & - & $\begin{array}{l}0.00905 \\
(0.00547)\end{array}$ & - & - \\
\hline Latino * Home sales & - & $\begin{array}{l}0.01186 * * * \\
(0.00355)\end{array}$ & - & - \\
\hline Proportion African American & $\begin{array}{l}0.00291 * * * \\
(0.00018)\end{array}$ & $\begin{array}{l}-0.00130^{* * *} \\
(0.00011)\end{array}$ & $\begin{array}{l}-0.02220 * * * \\
(0.00386)\end{array}$ & $\begin{array}{l}-0.02874 * * \\
(0.01005)\end{array}$ \\
\hline Proportion Latino & $\begin{array}{l}0.00111 * * * \\
(0.00018)\end{array}$ & $\begin{array}{l}-0.00002 \\
(0.00011)\end{array}$ & $\begin{array}{l}-0.03818 * * * \\
(0.00422)\end{array}$ & $\begin{array}{l}-0.02138 * * * \\
(0.00648)\end{array}$ \\
\hline Median housing value & - & - & $\begin{array}{l}-0.30834 * * * \\
(0 .) 9154)\end{array}$ & $\begin{array}{l}0.04256 \\
(0.09539)\end{array}$ \\
\hline Median income & $\begin{array}{l}-0.13269 * * * \\
(0.02699)\end{array}$ & $\begin{array}{l}0.03107 * \\
(0.01501)\end{array}$ & - & - \\
\hline Population density & $\begin{array}{l}0.00753 * * * \\
(0.00169)\end{array}$ & $\begin{array}{l}0.00040 \\
(0.00095)\end{array}$ & $\begin{array}{l}0.14867 * * * \\
(0.02921)\end{array}$ & $\begin{array}{l}0.10478 * * * \\
(0.03149)\end{array}$ \\
\hline
\end{tabular}

* Significant at $\alpha<.05$, ** significant at $\alpha<.01$, *** significant at $\alpha<.001 ;$ standard errors in parentheses 


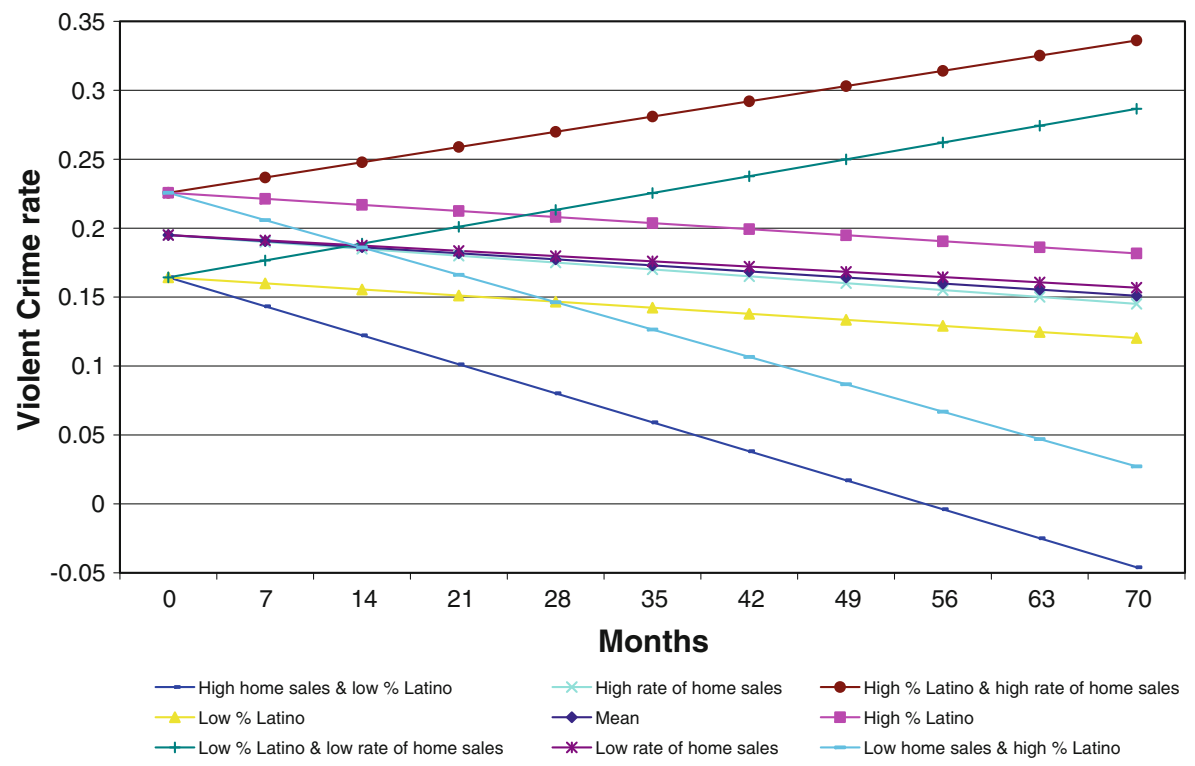

Fig. 2 Trajectory of the rate of violent crime 1992-1997 controlling for the percent Latino residents and the rate of home sales

rate of home sales, whereas the size of the African American population reduces both the rate of home sales over time and the rate of violent crime.

We next tested whether the racial/ethnic composition of the neighborhood moderated the potentially reciprocal relationship between crime and residential instability. We see no evidence that the effect of violent crime on subsequent home sales is moderated by the racial/ethnic composition of the neighborhood, as the interactions between violent crime and the two minority groups do not have a significant effect on the trajectory of home sales volatility over the subsequent years, as seen in Table 3 . Nonetheless, we highlight that violent crime remains a robust predictor of the housing sales volatility trajectory, and at approximately the same magnitude as the conditional model without the interaction effects, suggesting that violent crime induces mobility in all types of neighborhoods. On the other hand, we do see that the effect of home sales volatility on violent crime trajectories is moderated by the proportion Latino in the neighborhood. In neighborhoods with a larger proportion of Latino residents, increasing rates of home sales have the expected positive effect on the trajectory of violent crime over the subsequent years $(b=0.0119, p<.001)$. This illustrates that the relationship between the rate of home sales and the rate of violent crime varies as function of the size of the Latino population.

To provide a sense of the magnitude of the moderating relationship, Fig. 2 plots different trajectories of violent crime for various hypothetical neighborhoods with differing rates of home sales volatility and different size populations of Latinos. In this Figure, 'High' and 'Low' refer to one standard deviation above the mean and one standard deviation below the mean, respectively. We see that residential stability influences the direction of the violent crime trajectory: in highly Latino neighborhoods with a high rate of home sales (i.e. highly unstable), the trajectory of violent crime is positive. However, in highly Latino neighborhoods with a low rate of home sales (i.e. highly stable), the trajectory of crime is negative. 
Testing a Different Measure of Residential Stability

Up to this point we have seen a clear pattern of results: (1) violent crime appears to have a strong effect on the subsequent rate of residential instability in a neighborhood as measured by home sales volatility; (2) residential instability (measured by home sales volatility) appears to have little effect on subsequent trajectories of violent crime rates in neighborhoods; and (3) residential instability does appear to cause more subsequent violent crime in neighborhoods with a greater proportion of Latino residents. Nonetheless, we are employing a somewhat unorthodox measure of residential instability by only focusing on the mobility of homeowners. For our next set of analyses, we employ a more traditional measure of stability: our factor score combining the percent of new residents who moved to the tract within 5 years and the average length of residence in the tract in 1990. Higher values of the stability index indicate greater stability and low values indicate residential instability. We substituted the factor variable for the latent intercept of home sales volatility in the previous models and the difference between this index in 1990 and 2000 as an indicator of the change in residential stability over time. This change indicator is substituted for the latent trajectory of home sales volatility in the previous models; although this

Table 4 Regression results for full conditional model (including interaction effects) of the relationship between the rate of violent crime and change in the residential stability index, $N=585$

\begin{tabular}{|c|c|c|c|c|c|c|}
\hline \multirow[t]{2}{*}{ Parameter } & \multicolumn{3}{|l|}{ Model 1} & \multicolumn{3}{|l|}{ Model 2} \\
\hline & $\begin{array}{l}\text { Violent } \\
\text { crime } \\
\text { intercept }\end{array}$ & $\begin{array}{l}\text { Violent } \\
\text { crime slope }\end{array}$ & $\begin{array}{l}\text { Change in } \\
\text { stability } \\
\text { scale }\end{array}$ & $\begin{array}{l}\text { Violent } \\
\text { crime } \\
\text { intercept }\end{array}$ & $\begin{array}{l}\text { Violent } \\
\text { crime slope }\end{array}$ & $\begin{array}{l}\text { Change in } \\
\text { stability scale }\end{array}$ \\
\hline $\begin{array}{l}\text { Violent crime } \\
\text { intercept }\end{array}$ & - & - & $\begin{array}{l}-1.1466^{* * * *} \\
(0.28019)\end{array}$ & - & - & $\begin{array}{l}-1.38784 * * * \\
(0.28115)\end{array}$ \\
\hline $\begin{array}{l}\text { Residential } \\
\text { stability index } \\
(1990)\end{array}$ & - & $\begin{array}{l}-0.0060^{* * *} \\
(0.00234)\end{array}$ & - & - & $\begin{array}{l}-0.00671 * * \\
(0.00211)\end{array}$ & - \\
\hline $\begin{array}{l}\text { African American } \\
* \text { Violent crime }\end{array}$ & - & - & - & - & - & $\begin{array}{l}1.38907 \\
(0.99351)\end{array}$ \\
\hline $\begin{array}{l}\text { Latino } * \text { Violent } \\
\text { crime }\end{array}$ & - & - & - & - & - & $\begin{array}{l}1.42190 \\
(0.78344)\end{array}$ \\
\hline $\begin{array}{l}\text { African American } \\
* \text { Stability }\end{array}$ & - & - & - & - & $\begin{array}{l}0.00017^{*} \\
(0.00008)\end{array}$ & - \\
\hline Latino $*$ Stability & - & - & - & - & $\begin{array}{l}- \\
0.00047 * * * \\
(0.00007)\end{array}$ & - \\
\hline $\begin{array}{l}\text { Proportion African } \\
\text { American }\end{array}$ & $\begin{array}{l}0.00289 * * * \\
(0.00018)\end{array}$ & $\begin{array}{l}- \\
0.0010 * * * \\
(0.00012)\end{array}$ & $\begin{array}{l}0.00163 \\
(0.00159)\end{array}$ & $\begin{array}{l}0.0030 * * * \\
(0.00018)\end{array}$ & $\begin{array}{l}-0.0012 * * * \\
(0.00011)\end{array}$ & $\begin{array}{l}-0.00166 \\
(0.00349)\end{array}$ \\
\hline Proportion Latino & $\begin{array}{l}0.00109 * * * \\
(0.00018)\end{array}$ & $\begin{array}{l}0.00070 \\
(0.00011)\end{array}$ & $\begin{array}{l}0.00430 * * \\
(0.00151)\end{array}$ & $\begin{array}{l}0.00118 * * * \\
(0.00018)\end{array}$ & $\begin{array}{l}-0.00009 \\
(0.00011)\end{array}$ & $\begin{array}{l}0.00204 \\
(0.00223)\end{array}$ \\
\hline $\begin{array}{l}\text { Median housing } \\
\text { value }\end{array}$ & - & - & $\begin{array}{l}-0.05624 \\
(0.03205)\end{array}$ & - & - & $\begin{array}{l}-0.05791 \\
(0.03232)\end{array}$ \\
\hline Median income & $\begin{array}{l}-0.1369 * * * \\
(0.02711)\end{array}$ & $\begin{array}{l}0.04485 * * \\
(0.01682)\end{array}$ & - & $\begin{array}{l}-0.1113 * * * \\
(0.0702)\end{array}$ & $\begin{array}{l}0.01835 \\
(0.01643)\end{array}$ & - \\
\hline Population density & $\begin{array}{l}0.00743 * * * \\
(0.00169)\end{array}$ & $\begin{array}{l}-0.00112 \\
(0.00099)\end{array}$ & $\begin{array}{l}-0.0568 * * * \\
(0.01060)\end{array}$ & $\begin{array}{l}0.00808 * * * \\
(0.00169)\end{array}$ & $\begin{array}{l}-0.00166 \\
(0.00104)\end{array}$ & $\begin{array}{l}-0.05426 * * * \\
(0.01066)\end{array}$ \\
\hline
\end{tabular}

* Significant at $\alpha<.05$, ** significant at $\alpha<.01$, *** significant at $\alpha<.001 ;$ standard errors in parentheses 
is a less desirable measure given that it does not account for yearly changes, it does allow us to assess the robustness of our prior results.

The results using this alternative measure of residential stability generally mirror those presented above with one major exception, as shown in Table 4. By including renters in our residential stability index we find that residential stability has a significant negative impact on the violent crime trajectory, a relationship that was non-significant in our previous models. This is evidence of a reciprocal relationship between change in violent crime and change in residential stability: increases in residential instability are associated with increases in the trajectory of violent crime, but those increases in violence are also related to increased residential instability over time. Nonetheless, we point out that based on standardized coefficients, the effect of violent crime on the change in residential stability $(-0.3028)$ is twice the size of the effect of residential stability on the change in violent crime (-0.1436). Given that the instability of homeowners specifically had no effect on violent crime in our original models, this implies a differential relationship between residential stability and change in violence depending on whether or not the definition of residential (in)stability includes renters or focuses solely on homeowners. Such a possibility has not been previously raised in the literature.

As in the original models, when we take into account the racial/ethnic composition of the neighborhood in which residential stability occurs in the second model in Table 4, we again see that the effect of residential stability on violent crime trajectories is stronger in neighborhoods with more Latino residents. Residentially stable neighborhoods with more Latinos experience a negative trajectory of violent crime in subsequent years $(b=$ $-0.00047, p<.001)$. In addition, we see that by accounting for renters in our stability index, stable neighborhoods with more African Americans actually result in steeper increases in the violent crime trajectory in subsequent years $(b=0.00017, p<.05)$; a relationship that was in the same direction but non-significant in the models focusing exclusively on homeowners. This may be a function of the lower financial resources associated with renters as opposed to homeowners, who may be trapped in communities despite increases in violent crime because they are unable to find adequate affordable housing elsewhere. Indeed, a report on housing markets in California between 1990 and 1997 concluded that the supply of housing for lower income renters is extremely limited, particularly in metropolitan areas such as Los Angeles (Smith-Heimer 1999).

As further verification of the potential unique roles homeowners and renters play when measuring instability, additional models using a stability factor score including the percent homeowners replicated the pattern of findings from the latent trajectory models initially discussed (results not shown). That is, we created a stability index comprised of the average length of stay, the percent of residents in the same home for the past 5 years, and the percent homeowners. Models with this measure found a significant and negative effect of changes in violent crime on changes in residential stability, but no such effect of increased stability on changes in violent crime over time. This measure showed similar effects to our main models when accounting for the racial and ethnic composition of neighborhoods. This further substantiates the need to parse out renter and homeowner mobility, particularly in minority communities.

\section{Discussion}

This study has shed light on three important questions: (1) what is the relationship between the rate of violent crime and residential stability when accounting for the simultaneous 
reciprocal relationship; (2) are the effects of homeowner stability and neighborhood stability in general equivocal; and (3) how does the racial/ethnic composition of the community impact the violent crime-stability relationship. The majority of prior studies examining crime and residential instability only explore one side of the equation, but by using a dual latent trajectory model we were able to account for the reciprocal relationship between longitudinal changes in the rate of violent crime and residential instability at the same time. Additionally, we used a novel measure of instability-the rate of residential home sales-in order to specifically test the importance of homeowners in residential stability. Our findings suggest that the relationship between violent crime and home sales volatility may operate in only one direction when focusing specifically on homeowners: whereas our results failed to find a significant impact of homeowner turnover on the rate of violent crime as expected under a social disorganization framework, we did find that neighborhoods with more violent crime experienced increasing residential home sales over time. When using an alternative measure of residential stability that incorporates renters, we find some evidence of a reciprocal effect of violent crime on residential stability and residential instability on violence. Nonetheless, we still found that the effect of crime on the change in residential instability appeared almost twice as strong as the reverse effect.

The most important conclusion from our study is the robust finding that higher rates of violent crime in neighborhoods lead to increasing rates of residential instability. This finding was detected for both our housing volatility measure and our index of residential stability, and regardless of the racial/ethnic composition of the neighborhood. These findings are consistent with previous research showing that increasing crime rates can negatively affect the rate of homeownership (White 2001), can lead to residential outmobility (Morenoff and Sampson 1997), and that criminal victimization induces mobility (Dugan 1999). Our results support the idea that higher rates of violent crime increase residential turnover, but also indicate that instability is enduring over time. We found that a one percent increase in the violent crime rate was associated with a $1.5 \%$ increase in the trajectory of homes sold in an average tract. This likely represents the desire of residents to move away from areas with high rates of violent crime to safer areas.

A second important implication of our findings is that it may be important for scholars to consider the form of instability. Although violent crime increased subsequent levels of residential instability — regardless how we measured it—we generally found weaker effects of instability on changes in violent crime over time. There was no evidence that homeowner turnover affected subsequent levels of violent crime. Likewise, an instability index including a measure of the percent homeowners had no effect on changes in violent crime. Only an index focused entirely on the housing turnover of all residents showed a significant effect on the change in violent crime over time. It is possible that this represents poorer residents trapped by limited economic resources to relocate in response to crime increases. It is also possible that increased housing volatility in part represents the positive effects of gentrification through rehabilitated housing stock and a deconcentration of poverty (Atkinson 2004). Neighborhoods undergoing gentrification will experience high residential instability that may not necessarily lead to higher rates of crime. Research has already shown that homeowners have positive effects on the community (e.g. Campbell and Lee 1992; Oh 2004) and are a protective factor against crime (e.g. Hipp 2007b), but our results suggest that the residential stability of renters may nonetheless be important to take into account. These two effects-instability and homeownership-may have contradictory impacts on crime over time and the distinction is important to explicate.

Although we found no evidence that residential instability leads to more violent crime over time for neighborhoods in the housing volatility model in general, we did find that this 
effect was present in neighborhoods with high proportions of Latinos. Neighborhoods with a large Latino population and higher residential instability experienced steeper violent crime trajectories for both measures of residential instability. In contrast, highly Latino neighborhoods with low instability rates experienced a decreasing trajectory of violent crime. This suggests that stable Latino barrios (ethnic enclaves) may be a protective factor from violent crime. Whether this finding will be replicated in studies of other metro areas is an important research agenda for future work.

The fact that residential stability did not reduce violent crime trajectories in mostly African American neighborhoods was also notable. It is worth highlighting that this was the case regardless of how we measured residential instability. Furthermore, we found that the residential stability index was actually associated with increasing rates of violent crime in African American neighborhoods. The fact that this measure of stability that takes into account the presence of renters actually resulted in a steeper increase in violent crime may represent the limited mobility of poorer renters in such neighborhoods who are unable to find alternative affordable housing in safer areas. This highlights not only the importance of taking into account the racial/ethnic composition of the neighborhood in which such residential stability occurs, but also the form of this residential stability.

While this study has provided key insights into the complex relationship between violent crime, residential turnover, and race/ethnicity, some limitations should be acknowledged. First, we studied a relatively short time period during which Los Angeles, like the rest of the country, was experiencing a housing boom and a general decrease in violent crime. It would be a logical extension of this research to expand the years under study to account for the recent slowdown in the housing market (which could impact the ability of residents to sell their homes). Similarly, it may be advantageous to compare Los Angeles to another city. Of course, current formulations of social disorganization theory do not specify that the relationship between residential instability and crime rates will be moderated by the overall trajectory of crime in the larger city. This might suggest a particular scope condition for the social disorganization model: the theory only applies during periods in which overall crime is constant or increasing. To our knowledge, such a scope condition has never been put forward for the social disorganization theory, nor have theoretical reasons been given for why we should expect such a limitation on what is postulated as a more general theory. Nonetheless, we leave it to future research to test for such possible macro level effects on the relationship between crime and residential instability. Second, we cannot account for changes in the population characteristics over time. Because of data constraints we must rely on census data as a measure of neighborhood demographics, but it is likely that population changes occurred in Los Angeles during this time. Intercensal information on the racial/ethnic composition of tracts would allow us to track how changes in the racial/ethnic composition may be impacting the trajectories.

Despite these limitations, this study contributes to our knowledge of an important area of criminological research. Controlling for simultaneous relationships in neighborhoods is essential in order to fully understand the complex interactions between violent crime, residential stability, and racial/ethnic composition. Until we can fully understand how these three elements operate together to perpetuate crime, we will be unable to successfully implement policies or programs to either reduce crime or increase residential stability.

Open Access This article is distributed under the terms of the Creative Commons Attribution Noncommercial License which permits any noncommercial use, distribution, and reproduction in any medium, provided the original author(s) and source are credited. 


\section{References}

Adelman RM, Tsao H-S, Tolnay SE, Crowder KD (2001) Neighborhood disadvantage among racial and ethnic groups: residential location in 1970 and 1980. Sociol Q 42:603-632

Alba RD, Logan J, Stults B (2000) The changing neighborhood contexts of the immigrant metropolis. Soc Forces 79:587-622

Anderson E (1990) Streetwise: race, class and change in an urban community. Chicago Press, Chicago

Atkinson R (2004) The evidence on the impact of gentrification: new lessons for the Urban Renaissance? Eur J Hous Policy 4:107-131

Barrett A, Oropes RS, Kanan J (1994) Neighborhood context and residential mobility. Demography 31: 249-270

Bellair PE (1997) Social interaction and community crime: examining the importance of neighbor networks. Criminology 35:677-703

Bellair PE (2000) Informal surveillance and street crime: a complex relationship. Criminology 38:137-167

Blum T, Kingston PW (1984) Homeownership and social attachment. Sociol Perspect 27:159-180

Bolan M (1997) The mobility experience and neighborhood attachment. Demography 24:225-237

Breton R (1964) Institutional completeness of ethnic communities and the personal relations of immigrants. Am J Sociol 70:193-205

Bursik RJ (1986) Ecological stability and the dynamics of delinquency. Crime Justice 8:35-66

Bursik R, Grasmick H (1993) Neighborhoods and crime: the dimensions of effective community control. Lexington Books, New York

Campbell K, Lee B (1992) Sources of personal neighbor networks: social integration, need, or time? Soc Forces 70:1077-1100

Charles CZ (2003) The dynamics of racial residential segregation. Annu Rev Sociol 29:167-207

Crutchfield RD, Geerken MR, Gove WR (1982) Crime rate and social integration: the impact of metropolitan mobility. Criminology 20:467-478

Dugan L (1999) The effect of victimization on a household's moving decision. Criminology 37:903-931

Garcia RM, Taylor RB, Lawton BA (2007) Impacts of violent crime and neighborhood structure on trusting your neighbor. Justice Q 24:679-704

Garland C, Stokols D (2002) The effect of neighborhood reputation on fear of crime and inner-city investment. In: Aragones JI, Francescato G, Garling T (eds) Residential environments: choice satisfaction and behavior. Begin and Garvey, Westport CT

Henderson V (2007) Longitudinal associations between television viewing and body mass index among white and black girls. J Adolesc Health 41:544-550

Hipp JR (2007a) Block, tract, and levels of aggregation: neighborhood structure and crime and disorder as a case in point. Am Sociol Rev 72:659-680

Hipp JR (2007b) Income inequality, race, and place: does the distribution of race and class within neighborhoods affect crime rates? Criminology 45:665-697

Hunter A (1978) Symbols of incivility: social disorder and fear of crime in urban neighborhoods. Paper presented at the annual meeting of the American Society of Criminology, Dallas, TX, November

Iceland J, Wilkes R (2006) Does socioeconomic status matter? race, class, and residential segregation. Soc Probl 53:248-273

Kasarda JD, Janowitz M (1974) Community attachment in mass society. Am Sociol Rev 39:328-339

Kennedy P (1998) A guide to econometrics. MIT, Cambridge, MA

Krivo LJ, Peterson RD (1996) Extremely disadvantaged neighborhoods and urban crime. Soc Forces 75:619-648

Kubrin CE, Herting J (2003) Neighborhood correlates of homicide trends: an analysis using growth-curve modeling. Sociol Q 44:329-350

Lenzenweger MF, Willett JB (2007) Modeling individual change in personality disorder features as a function of simultaneous individual change in personality dimensions linked to neurobehavioral systems: The Longitudinal Study of Personality Disorders. J Abnorm Psychol 116:684-700

Liska AE, Bellair PE (1995) Violent-crime rates and racial composition: convergence over time. Am J Sociol 101:578-610

Liska AE, Lawrence JJ, Sanchirico A (1982) Fear of crime as a social fact. Soc Forces 60:760-771

Morenoff JD, Sampson RJ (1997) Violent crime and the spatial dynamics of neighborhood transition: Chicago, 1970-1990. Soc Forces 76:31-64

Nagin D (1999) Analyzing developmental trajectories: semi-parametric, group-based approach. Psychol Methods 4:139-177

Oh J-H (2004) Race/ethnicity, homeownership, and neighborhood attachment. Race Soc 7:63-77 
Pattillo ME (1998) Sweet mothers and gangbangers: managing crime in a black middle-class neighborhood. Soc Forces 76:747-774

Roncek D (1981) Dangerous places: crime and residential environment. Soc Forces 60:74-96

Roncek DW, Maier PA (1991) Bars, blocks, and crimes revisited: linking the theory of routine activities to the empiricism of 'hot spots'. Criminology 29:725-753

Ross M (1977) Economics, opportunity and crime. Renouf, Montreal, Canada

Rountree PW, Warner BD (1999) Social ties and crime: is the relationship gendered? Criminology 37: 789-813

Sampson RJ, Groves WB (1989) Community structure and crime: testing social-disorganization theory. Am J Sociol 94:774-802

Sampson RJ, Raudenbush SW (2004) Seeing disorder: neighborhood stigma and the social construction of "Broken Windows". Soc Psychol Quart 67:319-342

Sampson RJ, Raudenbush SW, Earls F (1997) Neighborhoods and violent crime: a multilevel study of collective efficacy. Science 277:918-992

Schwartz AE, Susin S, Voicu I (2003) Has falling crime driven down New York City's real estate boom? J Hous Res 14:101-135

Shaw C, McKay HD (1942) Juvenile delinquency and urban areas. University of Chicago Press, Chicago

Skogan W (1990) Disorder and decline: crime and the spiral of decay in American neighborhoods. Free Press, New York

Smith WR, Frazee SG, Davison EL (2000) Furthering the integration of routine activity and social disorganization theories: small units of analysis and the study of street robbery as a diffusion process. Criminology 38:489-523

Smith-Heimer M (1999) The state of California's housing markets 1990 - 1997, statewide housing plan update. Report for the California Department of Housing and Community Development, Housing Policy Division. Berkeley CA

South SJ, Crowder K (1997a) Escaping distressed neighborhoods: individual, community, and metropolitan influences. Am J Sociol 102:1040-1084

South SJ, Crowder K (1997b) Residential mobility between cities and suburbs: race, suburbanization, and back-to-the-city moves. Demography 34:525-538

South SJ, Crowder K, Chavez E (2005) Exiting and entering high-poverty neighborhoods: latinos, blacks and anglos compared. Soc Forces 84:873-900

Speare A, Goldstein S, Frey W (1975) Residential mobility, migration, and metropolitan change. Ballinger, Cambridge, CA

Stark R (1987) Deviant places: a theory of the ecology of crime. Criminology 25:893-909

Taylor R (1996) Neighborhood responses to disorder and local attachments: the systemic model of attachment, social disorganization, and neighborhood use value. Sociol Forum 11:41-74

Tita G, Petras T, Greenbaum R (2006) Crime and residential choice: a neighborhood level analysis of the impact of crime on housing prices. J Quant Criminol 22:299-317

Turner MA, Ross SL (2003) Discrimination in metropolitan housing markets: phase 2-Asiansand Pacific islanders of the HDS 2000. U.S. Department of Housing and Urban Development, Washington, DC

Turner MA, Ross SL, Galster G, Yinger J (2002) Discrimination in metropolitan housing markets: national results from phase 1 of the housing discrimination study (HDS). U.S. Department of Housing and Urban Development, Washington, DC

Warner B, Pierce G (1993) Reexamining social disorganization theory using calls to the police as a measure of crime. Criminology 31:493-517

Warner B, Rountree PW (1997) Local social ties in a community and crime model: questioning the systemic nature of informal social control. Soc Forces 44:520-536

White G (2001) Home ownership: crime and the tripping and trapping processes. Environ Behav 33: 325-342

Wilson KL, Portes A (1980) Immigrant enclaves: an analysis of the labor market experiences of Cubans in Miami. Am J Sociol 86:295-319

Windle M, Windle R (2001) Depressive symptoms and cigarette smoking among middle adolescents: prospective associations prospective associations and intrapersonal and interpersonal influences. J Consult Clin Psychol 69:215-226 